\title{
Ação fungitóxica do óleo essencial de Tanaecium nocturnum (Barb. Rodr.) Bur. e K. Shum sobre o Aspergillus flavus isolado da castanha-do-Brasil (Bertholletia excelsa)
}

\author{
Flávio Araújo PIMENTEL ${ }^{1}$, Maria das Graças CARDOSO², Luis Roberto BATISTA, Luiz Gustavo de Lima \\ GUIMARÁES ${ }^{4}$, Daiani Maria SILVA ${ }^{5}$
}

\begin{abstract}
RESUMO
Neste trabalho, avaliou-se a capacidade fungitóxica do óleo essencial de folhas frescas de Tanaecium nocturnum sobre o Aspergillus flavus isolado da castanha-do-brasil, por meio das técnicas de contato e fumigação. Pelos resultados dos bioensaios realizados até 10 dias de incubação, verificou-se que a inibição total do crescimento micelial ocorreu quando se utilizou o óleo essencial nas concentraçóes de 782 ppm (técnica de contato) e 1000 ppm (técnica de fumigação). Em ambas as técnicas, o óleo essencial inibiu a esporulação a partir da concentração de 500 ppm. Observou-se que nos cinco primeiros dias de incubação não houve diferença significativa nos resultados apresentados pelas duas técnicas estudadas, havendo a partir daí uma reduçáo da atividade do óleo essencial nas concentraçóes inferiores a 1000 ppm pelo teste de fumigação. A ação fungitóxica do óleo essencial sobre o microrganismo estudado pode ser atribuída à presença do benzaldeído (composto majoritário do óleo essencial estudado), em associaçáo com outros compostos também presentes nesse óleo essencial, tais como; álcool benzílico, benzoato de benzila e mandelonitrila.
\end{abstract}

PALAVRAS-CHAVE: Óleo essencial, ação fungitóxica, Tanaecium nocturnum, Aspergillus flavus, Bertholletia excelsa.

\section{Fungitoxic action of the essential oil of Tanaecium nocturnum (Barb. Rodr.) Bur. and K. Shum on Aspergillus flavus isolated from the Brazil nut (Bertholletia excelsa)}

\begin{abstract}
The present work sought to evaluate the fungitoxic activity of the essential oil from fresh Tanaecium nocturnum fresh leaves on Aspergillus flavus isolated from Brazil nuts, using contact and fumigation techniques. The results of bioassays performed up to 10 days of incubation demonstrated that total inhibition of mycelial growth occurred when using the essential oil at concentrations of $782 \mathrm{ppm}$ (contact technique) and $1000 \mathrm{ppm}$ (fumigation technique). In both techniques, the essential oil inhibited the formation of spores at the concentration of $500 \mathrm{ppm}$. No significant difference in the results presented by the two techniques was observed in the first five days of incubation. After this period, the essential oil showed a reduction in activity at concentrations lower than $1000 \mathrm{ppm}$ in the fumigation test. The fungitoxic activity of the essential oil on the organism studied can be attributed to the presence of benzaldehyde (major component of the essential oil), in combination with other compounds also present in this oil, such as, benzyl alcohol, benzyl benzoate and mandelonitrila.
\end{abstract}

KEYWORDS: Essential oil; fungitoxic action; Tanaecium nocturnum, Aspergillus flavus, Bertholletia excelsa.

\footnotetext{
${ }_{1}$ Embrapa Agroindústria Tropical. E-mail: flavio.pimentel@cnpat.embrapa.br

2 Universidade Federal de Lavras. E-mail: mcardoso@ufla.br

${ }^{3}$ Universidade Federal de Lavras. E-mail: luisrb@ufla.br

${ }^{4}$ Universidade Federal de Lavras. E-mail: mcardoso@ufla.br

${ }^{5}$ Universidade Federal de Lavras. E-mail: luisrb@ufla.br
} 


\section{INTRODUÇÃO}

A Floresta Amazônica detém a mais notável e diversificada fonte de produtos naturais do planeta. Devido a sua grande biodiversidade, existe uma elevada demanda por pesquisas em produtos florestais, visando ao fornecimento de informaçôes científicas para apoiar políticas de desenvolvimento sustentável com proteção aos seus ecossistemas. Entre os recursos naturais existentes, destacam-se a castanha-do-Brasil e as espécies produtoras de óleos essenciais (Müller et al., 1995; Pletsch e Sant'Ana, 1995; Chaar, 2000).

A castanha-do-Brasil possui participação significativa na geração de divisas para a regiâo, cujas exportaçôes para os mercados internos e externos têm ocupado importantes espaços na indústria de cosméticos (óleos, cremes, xampus, etc) e, de forma mais acentuada, na área de alimentos (amêndoas, farinha, coberturas de sorvetes, etc). Sua produção extrativista é considerada orgânica, uma vez que não são utilizados adubaçôes e defensivos químicos para o seu manejo (Souza, 1984; Cavalcante, 1996). No entanto, o baixo nível tecnológico característico da cadeia produtiva, associado às condiçóes climáticas (umidade e precipitação pluviométricas elevadas) no período de colheita (novembro a março), tem favorecido a contaminação das amêndoas em casca, principalmente por fungos produtores de aflatoxinas e, mais especificamente, pelo Aspergillus flavus. Esses problemas constituem um forte entrave para a comercialização do produto, principalmente no mercado externo, dado o rigoroso controle de países europeus e Estados Unidos em relação aos níveis de toxinas presentes nos alimentos. Com esses problemas encontrados, os habitantes, juntamente com as instituiçóes governamentais e não-governamentais, vêm buscando alternativas que reduzam os riscos de contaminaçôes, sem que haja descaracterização da cadeia produtiva, enfatizando, nesse sentido, a possibilidade da utilização de substâncias naturais encontradas nas localidades de produção (Souza, 2004).

Os organismos vegetais, na sua maioria, náo caracterizados quimicamente, são um universo rico e complexo de compostos orgânicos, com inúmeros centros estereogênicos que participam ativamente do seu crescimento e desenvolvimento. Tais compostos, definidos como metabólitos secundários, são originados por vias biossintéticas alternativas e podem ser caracterizados como elementos de diferenciação e especialização celular, atuando com função de defesa e perpetuação do vegetal no ecossistema (Wink, 1990). Entre esses, destacam-se os óleos essenciais, que apresentam larga atividade biológica, entre elas, a fungitóxica (Müller-Riebau et al., 1995).

Entre as espécies amazônicas produtoras de óleos essenciais com potencial antiaflatogênico a serem testados, encontrase a Tanaecium nocturnum (Barb. Rodr.) Bur. e K. Shum, pertencente à família Bignoniaceae. Conhecida como cipó vick ou cipó-carimbó, é uma planta trepadeira, cujas partes apresentam forte cheiro, característico de amêndoas amargas. Suas folhas sấo utilizadas externamente pela população como analgésico. Os índios da aldeia de Gotira, localizada às margens do rio Fresco, afluente do rio Xingu, utilizam o cipó para combater abelhas e formigas (saúvas), bem como para descongestionar vias respiratórias (Gottlieb et al., 1981; Ming, 1995).

O uso de técnicas de contato ou fumigação com óleos essenciais, extraídos de várias espécies vegetais, com potenciais inseticidas e fungicidas, para controle de pragas de gráos armazenados, tem sido nos últimos anos bastante difundida em diversos países (Chu et al., 2001; Suhr e Nielsen, 2003; Brito et al, 2006; Estrela et al., 2006). Particularmente com relação ao óleo essencial de T. nocturnum, destaca-se o efeito inseticida contra Sithophilus zeamais Motsch. obtido por Fazolin et al. (2007) - Acta Amazonica- vol. 37 (4) p. 599 -604 .

Diante do exposto, objetivou-se com este trabalho avaliar in vitro a toxicidade do óleo essencial do cipó vick sobre o Aspergillus flavus isolado da castanha-do-Brasil.

\section{MATERIAL E MÉTODOS}

O material genético foi coletado de população nativa de cipó vick, situada na Reserva Florestal da Embrapa Acre, localizada no município de Rio Branco, AC. Para a identificação da espécie, uma excicata foi enviada para o Instituto Agronômico do Norte (IAN), localizado em BelémPA. A equipe de botânicos do Herbário do IAN classificou como Tanaecium nocturnum (Barb. Rodr.) Bur \& K. Shum. (Bignoniaceae), utilizando-se como padrão a excicata de $\mathrm{n}^{\circ}$ de registro 179350 daquele Instituto.

A colheita foi realizada no mês de janeiro/2005, entre 8 e 10 horas, desprendendo o cipó das árvores e cortando-se a parte aérea da planta a $10 \mathrm{~cm}$ acima do solo. A temperatura local encontrava-se em torno de $25^{\circ} \mathrm{C}$. Em seguida, as plantas foram submetidas às operaçōes de desfolha e seleção, descartando-se os materiais atacados por praga ou doenças. Posteriormente, o material vegetal foi acondicionado em caixas de isopor, sob refrigeração (gelo) e transportado via aérea para o Laboratório de Química Orgânica, da Universidade Federal de Lavras, MG, para a realização das avaliaçôes fitoquímicas.

Para a determinaçáo da umidade, utilizaram-se 5 gramas de folhas frescas picadas, emergidas em $50 \mathrm{~mL}$ de ciclohexano $\left(\mathrm{C}_{6} \mathrm{H}_{12}\right)$. A matéria-prima foi suspensa no respectivo solvente e colocado em balâo volumétrico com capacidade para $250 \mathrm{~mL}$, acoplado a um condensador com coletor volumetricamente graduado. $\mathrm{O}$ aquecimento foi realizado por meio de manta aquecedora, controlando-se a temperatura para $100 \pm 5^{\circ} \mathrm{C}$. Após o processo de destilação, realizado em 3 horas, quantificou-se 
o volume de água presente na matéria-prima. A umidade foi calculada levando-se o teor de água contido em 100 gramas da amostra (AOCS, 1994; Pimentel et al., 2006).

A extração do óleo essencial foi realizada por meio de hidrodestilação, utilizando um aparelho Clevenger modificado e acoplado a um baláo de $1 \mathrm{~L}$, no qual foram colocados 50 gramas de folhas frescas picadas, juntamente com $500 \mathrm{~mL}$ de água destilada. O tempo de extração, determinado por meio de testes preliminares, foi de 4 horas, contado a partir do momento de ebulição. O óleo essencial foi extraído da fase aquosa utilizando-se o diclorometano $(3 \times 30 \mathrm{~mL})$. As fraçôes orgânicas foram reunidas, secas com sulfato de magnésio anidro, filtradas e o solvente removido sob pressáo reduzida em evaporador rotativo à $35^{\circ} \mathrm{C}$. A massa do óleo obtida foi determinada por pesagem em balança analítica com precisão de $0,1 \mathrm{mg}$. O óleo obtido foi transferido para frascos de vidro com tampa rosqueável (septo de silicone) e armazenado em geladeira a $10{ }^{\circ} \mathrm{C}$ (Craveiro et al., 1981; Barbosa e Barbosa, 2006).

Para a determinação da densidade do óleo essencial, empregou-se o método de picnometria (picnômetros Hubbard Cormick de $30 \mathrm{~mL}$ ), utilizando água como fluido picnométrico (calibração). A pesagem foi realizada com três repetiçôes em balança analítica com precisão de $0,1 \mathrm{mg}$ (Schoch e Leach, 1964; Mohsenin, 1970). O óleo essencial foi submetido à caracterização química por Pimentel et al. (2008).

As avaliaçóes da atividade antifúngica do óleo essencial de Tanaecium nocturnum (cipó vick) foram realizadas com cepas puras de Aspergillus flavus produtora de aflatoxina, isoladas da castanha-do-Brasil, fornecidas pela Embrapa Acre. Os estudos in vitro da atividade antifúngica do óleo essencial de cipó vick foi realizado utilizando o meio de cultura CYA (Czapek Yeast Autolysate Agar - sacarose 57,68\%, nitrato de sódio $5,77 \%$, fosfato dipotássico $1,92 \%$, sulfato de magnésio $0,002 \%$, cloreto de potássio $0,96 \%$, sulfato ferroso $0,02 \%$, agar bacteriológico $28,84 \%$ e extrato de levedura $4,81 \%$ ), usando-se placas de Petri (Pitt e Hocking, 1999). Para avaliar a toxicidade do óleo essencial, foram utilizados os seguintes processos:

Foram realizados testes preliminares com o óleo essencial, para estabelecer intervalos de quantidades capazes de provocar inibiçôes crescentes do Aspergillus flavus, bem como do solvente utilizado, levando-se em consideração os aspectos de solubilidade e de atoxicidade ao microrganismo.

Para avaliação do método de contato o óleo essencial foi diluído em diferentes proporçôes em dimetil sulfóxido (DMSO). Assim que o meio de cultura acondicionado em erlenmeyer atingiu aproximadamente $45^{\circ} \mathrm{C}$, adicionou-se a soluçáo, homogeneizando com bastão de vidro. Em seguida, essa foi quantitativamente transferida para as placas de Petri $(20 \mathrm{~mL})$. Após a solidificaçấo do meio de cultura, realizou-se a inoculação do fungo em um ponto central da placa. Como tratamentos, o óleo essencial foi adicionado nas dosagens de $\mathrm{T} 1=125 ; \mathrm{T} 2=250 ; \mathrm{T} 3=500$ e T4 $=1000 \mathrm{ppm}$ da mistura (meio de cultura + DMSO). A testemunha relativa (DMSO) foi incorporada na dosagem de $250 \mathrm{ppm}$ de substrato (Jham et al., 2005; Wang et al., 2005; Viegas et al., 2005;).

Utilizando o mesmo meio de cultura e procedimento de inoculaçáo do fungo anteriormente citado, no processo de biofumigação o óleo essencial puro foi aplicado com micropipeta em superfície de papel de filtro de $4,0 \mathrm{~cm}$ de diâmetro, fixado na tampa da placa de Petri $\left(V_{\text {interno }}=110 \mathrm{~cm}^{3}\right)$. Para isso, utilizaram-se os mesmos volumes de óleo essencial, correspondentes a cada tratamento do processo de contato (Naakahara et al., 2003; Brito, 2006; Estreta et al., 2006).

Em ambos os processos de aplicação, após cinco e dez dias da incubaçấo em BOD à temperatura de $25^{\circ} \mathrm{C}$ e fotoperíodo de 12 horas, efetuou-se as mediçôes ortogonais do diâmetro das colônias, tendo como referência o seu desenvolvimento na placa-controle (testemunha absoluta $=\mathrm{TA}$ ). Para a contagem de esporos, foram utilizados câmara de Newbauer e microscópio (Pitt e Hocking, 1999).

Os experimentos foram conduzidos no delineamento inteiramente casualizado, com três repetiçôes. As variáveis relativas à esporulação e ao crescimento micelial foram submetidas a análises de variâncias e respectivamente às comparaçôes múltiplas de médias feitas pelo teste Tukey (5\%) e à análise de regressão, utilizando-se o programa SISVAR (Ferreira, 2000).

\section{RESULTADOS E DISCUSSÃO}

As folhas frescas com umidade de $62 \%$ apresentaram um teor de óleo essencial de 1,55\% (b.s.) com densidade de $1,008 \mathrm{~g} / \mathrm{cm}^{3}$. Pimentel et al. (2008) identificaram doze compostos na constituição química do óleo essencial das folhas frescas de Tanaecium nocturnum perfazendo um total de $94,37 \%$ de sua constituição, sendo o benzaldeído $(74,70 \%)$ o constituinte majoritário, seguido pelo álcool benzílico $(7,89 \%)$, mandelonitrila $(3,96 \%)$, benzoato de benzila $(3,28 \%)$ e de outros compostos presentes em concentraçôes inferiores a $1 \%$. A presença destes constituintes no óleo essencial desta espécie vegetal também tem sido relatado por Gottlieb (1981) e Fazolin et al. (2007).

Nos tratamentos com óleo essencial, verificou-se que, com cinco e dez dias de incubação, houve uma redução do crescimento micelial com o aumento da concentração do óleo essencial, utilizando a técnica de contato. Essa reduçấo aumentou de $31,52 \%$ (125 ppm) para 100\% (782 ppm) no décimo dia da incubação. A inibiçãoo total, no quinto e décimo dia, ocorreu respectivamente, nas concentraçôes de 781 e 782 ppm do óleo essencial. As equaçóes de regressóes obtidas com 
cinco e dez dias de incubação apresentaram coeficientes de determinaçáo com valores bastante próximos $\left(\mathrm{R}^{2}{ }_{5 \text { dias }}=98,9 \%\right.$ e $\left.\mathrm{R}^{2}{ }_{10 \text { dias }}=98,3 \%\right)$ e por isso não será possível distinguir as representaçôes gráficas (Figura 1). No contexto geral da técnica de contato não houve diferença significativa entre os cinco e dez dias, no entanto optou-se por apresentar as equaçóes de cada dia, para melhor entendimento e visualização do processo.

Com cinco dias de incubação, a técnica de fumigação apresentou efeito semelhante do óleo essencial na inibição micelial, em relação à aplicação por meio de contato. Diferenças significativas ocorreram na técnica de fumigação com relaçáo às doses que promoveram a inibiçấo total do fungo em função do tempo de incubação. Com essa técnica, verificou-se que as doses inibitórias foram de 788 ppm e 1000 ppm, respectivamente, para cinco e dez dias da incubação (Figura 2). Avaliando os dois processos de controles micelial, constatou-se que aos cinco dias de incubação do Aspergillus flavus a técnica de contato apresentou baixa superioridade

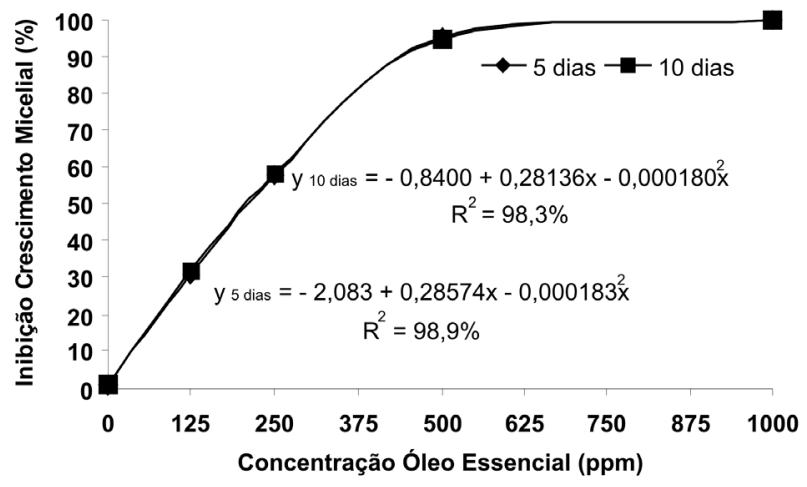

Figura 1 - Representação gráfica, equação de regressão e coeficiente de determinação da inibição do crescimento micelial do $A$. flavus submetido a diferentes concentrações do óleo essencial utilizando a técnica de contato após cinco e dez dias de incubação.

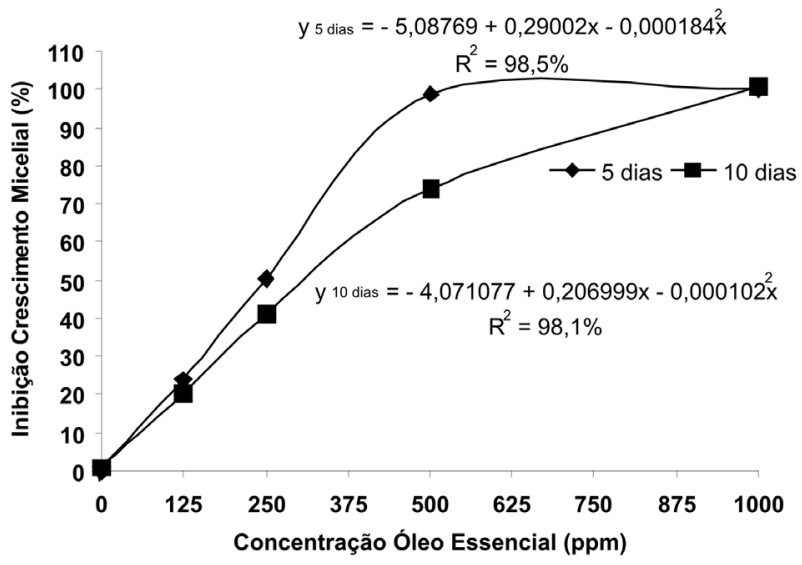

Figura 2 - Representação gráfica, equação de regressão e coeficiente de determinação da inibição do crescimento micelial do $A$. flavus submetido a diferentes concentrações do óleo essencial utilizando a técnica de fumigação após cinco e dez dias de incubação. em relação à de fumigaçáo, com inibição total obtida nas concentraçóes de 781 ppm e 788 ppm, respectivamente. No entanto, estes efeitos foram significativos aos dez dias de incubação, utilizando-se concentraçóes inibitórias de 782 ppm no contato e 1000 ppm na fumigação (Figuras 1 e 2).

Observou-se uma redução significativa da esporulação com o aumento da concentração do óleo essencial, em ambos os procedimentos utilizados (Tabela 1). Aos cinco dias, no processo de fumigaçáo, detectou-se uma redução da densidade de esporos entre os tratamentos T1 $\left(2 \times 10^{6}\right)$ e T2 $\left(0,68 \times 10^{6}\right)$. Com dez dias, ocorreram reduçôes entre esses tratamentos em todas as técnicas de aplicação do óleo essencial (contato, $\mathrm{T} 1=2,3310^{6}$ e T2 $=1,43 \times 10^{6}$ ) e (fumigação, $\mathrm{T} 1=4,37 \times$ $10^{6}$ e T2 $\left.=0,74 \times 10^{6}\right)$. Na técnica de contato, com exceçáo dos tratamentos T3 e T4, os demais apresentaram aumentos significativos de densidades de esporos entre cinco e dez dias. $\mathrm{Na}$ técnica de fumigação, apenas a testemunha $\left(3,50 \times 10^{6}\right.$ e 4,63 $\left.\times 10^{6}\right)$ e o tratamento $\mathrm{T} 1\left(0,68 \times 10^{6}\right.$ e $\left.0,74 \times 10^{6}\right)$ apresentaram aumentos significativos na produção de esporos. Em ambas, a inibiçáo total da geminação de esporos ocorreu a partir do tratamento T3 (500 ppm) (Tabela 1).

Com relação aos aspectos morfológicos, constatou-se nas testemunhas, absoluta e relativa, a presença de conídios de coloração esverdeada. Nos demais tratamentos que continham o óleo essencial, os conídios apresentavam-se incolores.

Os resultados da atividade fungitóxica de Tanaecium nocturnum estấo condizentes com os diversos efeitos biológicos de óleos essenciais relatados por diversos autores. Os principais constituintes do óleo essencial utilizado, tais como, benzaldeído, álcool benzílico e benzoatos, têm sido pesquisados e seus

Tabela 1 - Valores médios da produção de esporos em função do efeito fungitóxico do óleo essencial utilizando as técnicas de contato e fumigação.

\begin{tabular}{|c|c|c|c|c|}
\hline \multirow{3}{*}{ Tratamentos } & \multirow{2}{*}{\multicolumn{2}{|c|}{ 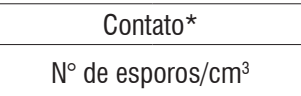 }} & \multicolumn{2}{|c|}{ Fumigação** } \\
\hline & & & \multicolumn{2}{|c|}{$N^{\circ}$ de esporos $/ \mathrm{cm}^{3}$} \\
\hline & 5 dias & 10 dias & 5 dias & 10 dias \\
\hline TA & $3.50 \times 10^{6} \mathrm{aA}$ & $4.63 \times 10^{6} \mathrm{aB}$ & $3.50 \times 10^{6} \mathrm{aA}$ & $4.63 \times 10^{6} \mathrm{aB}$ \\
\hline DMSO & $3.63 \times 10^{6} \mathrm{aA}$ & $5.00 \times 10^{6} \mathrm{aB}$ & - & - \\
\hline $\mathrm{T} 1=125 \mathrm{ppm}$ & $0.45 \times 10^{6} \mathrm{bA}$ & $2.33 \times 10^{6} \mathrm{bB}$ & $2.00 \times 10^{6} \mathrm{bA}$ & $4.37 \times 10^{6} \mathrm{aB}$ \\
\hline $\mathrm{T} 2=250 \mathrm{ppm}$ & $0.45 \times 10^{6} \mathrm{bA}$ & $1.43 \times 10^{6} \mathrm{CB}$ & $0.68 \times 10^{6} \mathrm{cA}$ & $0.74 \times 10^{6} \mathrm{bA}$ \\
\hline $\mathrm{T} 3=500 \mathrm{ppm}$ & $0.00 \mathrm{cA}$ & $0.00 \mathrm{dA}$ & $0.00 \mathrm{dA}$ & $0.00 \mathrm{cA}$ \\
\hline $\mathrm{T} 4=1000 \mathrm{ppm}$ & $0.00 \mathrm{cA}$ & $0.00 \mathrm{dA}$ & $0.00 \mathrm{dA}$ & $0.00 \mathrm{cA}$ \\
\hline
\end{tabular}

Médias seguidas de mesma letra, sendo minúscula na coluna e maiúscula na linha, para cada técnica de aplicação, não diferem entre si pelo teste de Tukey a $5 \%$ de probabilidade.

${ }^{\star} \mathrm{CV}(\%)=19,31$ Média Geral $=1,79 \times 10^{6}{ }^{*} \mathrm{CV}(\%)=12,16$ Média Geral $=1,59$ $\times 10^{6}$.

Means followed by the same small letter in a column or the same capital letter in a row Means followed by the same small letter in a colum
do not differ by the Tukey test at $5 \%$ of probability.

${ }^{*} \mathrm{CV}(\%)=19.31$; Overall average $=1.79 \times 10^{6}{ }^{\star *} \mathrm{CV}(\%)=12.16$; Overall average $=1.59 \times 10^{6}$. 
resultados confirmam atividades antifúngicas (Krebs et al., 1983; Devarajan et al., 2002; Vaughn e Spencer, 2004; Silva et al., 2005). Quando aplicados isoladamente, o benzaldeído tem apresentado citotoxicidade contra Aspergillus ninger, $R$. solani, Laetiporus sulphureus, Coriolus versicolor e Cândida albicans; o álcool benzílico em relação aos Staphylococcus aureus, Escherichia coli e Cândida albicans; os benzoatos contra Cladosporium cladosporioides e Cladosporium sphaerospermum. Efeito fungitóxico (inibição do desenvolvimento micelial) contra o Aspergillus flavus também tem sido relatados com a aplicação do óleo essencial de Cinnamomum zeilanicum Breym. Nas análises da composição química do óleo essencial dessa espécie, também foi evidenciada a presença de benzaldeído e de benzoato de benzila (Lima et al., 2005; Viegas, 2005). As indicaçóes da presença de mandelonitrila e de benzoato de mandelonitrila no óleo essencial, embora muito instáveis, podem estar potencializando o efeito fungitóxico do óleo, devido ao elevado grau de toxicidade desses metabólitos secundários (Darling et al., 2001).

Apesar de neste trabalho a produção de aflatoxina não ter sido avaliada, pesquisadores comprovam uma forte influência da reprodução e do crescimento micelial do fungo com a presença dessa micotoxina. De acordo com Brodhagen e Keller (2006), um decréscimo na esporulação do Aspergillus flavus reprime a produção de metabólitos secundários (aflatoxinas B1 e B2). Isso ocorre devido à existência de uma rota metabólica, que é controlada pela proteína G. Fatores como estresse, virulência e principalmente externos são os responsáveis pela reduçáo da esporulação. Kumar et al. (2008) avaliaram o efeito do óleo essencial de Thymus vulgaris sobre o crescimento micelial e a produção de aflatoxina B1 produzida por Aspergillus flavus. Os resultados apresentaram uma total inibição do crescimento micelial quando presente no meio de cultura na concentração de 700 ppm. Esse óleo essencial também apresentou atividade sobre a produção de aflatoxina $\mathrm{B}_{1}$, havendo um decréscimo em sua produçáo pelo microrganismo com o aumento da concentração desta essência no meio, até atingir a completa inibição na concentração de $600 \mathrm{ppm}$. Com base nesse aspecto, provavelmente a produção de aflatoxina pode ter sido reprimida, com o aumento da quantidade de óleo essencial aplicada.

O efeito antifúngico do óleo essencial depende da composição química e do método de aplicação (Chu et al., 2001; Suhr e Nielsen, 2003). Alguns compostos fenólicos, como timol e eugenol, têm sido mais eficientes quando aplicados diretamente ao meio de cultura, enquanto compostos menores, como o alil isotiocianato e citral são mais eficazes quando utilizados por meio de fumigação (Suhr e Nielsen, 2003). Neste trabalho, constatou-se uma superioridade da técnica de contato em relação à fumigação para a inibição micelial em dosagens do óleo essencial inferiores a 1000 ppm. Para a esporulação, os resultados não foram expressivos.

\section{CONCLUSÕES}

Pelos resultados dos bioensaios realizados até 10 dias de incubação, verificou-se que a inibição total do crescimento micelial de Aspergillus flavus ocorreu quando utilizou-se o óleo essencial nas concentraçóes de $782 \mathrm{ppm}$ na técnica de contato e 1000 ppm na técnica de fumigação. Em ambas as técnicas, o óleo essencial inibiu a esporulação a partir da concentração de 500 ppm.

A ação fungitóxica do óleo essencial sobre o Aspergillus flavus pode ser provavelmente atribuída à presença do benzaldeído, em associaçáo com álcool benzílico, benzoato de benzila e mandelonitrila.

\section{AGRADECIMENTOS}

À EMBRAPA - Acre, ao Departamento de Química da Universidade Federal de Viçosa (UFV), ao Conselho Nacional de Desenvolvimento Científico e Tecnológico $(\mathrm{CNPq})$ e à Fundaçáo de Apoio Pesquisa e Extensão de Minas Gerais (FAPEMIG), pelo auxílio financeiro e bolsas concedidas.

\section{BIBLIOGRAFIA CITADA}

AOCS Official Method Da2b-42. 1994. Official Methods and Recommended Practices of the American Oil Chemists Society. American Oil Chemists Society, Champaign, IL, USA.

Barbosa, F.F.; Barbosa, L.C.A. 2006. Influência da temperatura do ar de secagem sobre o teor e a composição química do óleo essencial de Lippia alba (Mill.) N, E. Brown. Quimica Nova, 29: 1221-1225.

Brito, J.P.; Oliveira, J.E.M.; Bortoli, S.A. 2006. Toxidade de óleos essenciais de Eucalyptus ssp. sobre Callosobruchus maculants (Coleóptera : Bruchidae). Revista de Biologia e Ciências da Terra, 6: 96-103

Brodhagen, M.; Keller, N.P. 2006. Signalling pathways connecting mycotoxin prodution and sporulation. Molecular Plant Pathology, 7: 285-301.

Cavalcante, P.B. 1996. Frutas comestiveis da Amazônia. MPEG, Belém. 279 pp.

Chaar, J.S. 2000. Estudos analíticos e modificação química por acetilação do linalol contido no óleo essencial da espécie Aniba duckei Kostermans. Tese de doutorado, Universidade de São Paulo, São Carlos, São Paulo. 125 pp.

Chu, C.L.; Liu, W.T.; Zhou, T. 2001. Fumigation of sweet cherries with thymol and acetic acid to reduce postharvest brown rot and blue mold rot. Fruits, 52: 123-129.

Craveiro, A.A.; Fernandes, A.G.; Andrade, C.H.S.; Matos, F.J.A.; Alencar, J.W.; Machado, M.I.L. 1981. Óleos essenciais de plantas do Nordeste. Universidade Federal do Ceará, Fortaleza, Ceará. 209 pp. 
Darling, C.; Schoroeder, F.; Meinwald, J.; Eisner, M.; Eisner, T. 2001. Production of a cyanogenic secretion by a thyridid caterpillar (Calindoea trifascialis, Thyrididae, Lepdoptera). Naturwissenschaften, 88: 306-309.

Devarajan, T.; Sreeyapureddy, A.; Thammineni, P.; Reddy, P.N.; Ramachandraiah, O.S. 2002. Essential oil constituents and in vitro antimicrobial activity of Decalepis hamiltonii, roots against foodborn pathogens. Journal of Agricultural and Food Chemistry, 50: 3147-3149.

Estrela, J.L.V.; Fazolin, M.; Catani, V.; Alércio, M.R.; Lima, M.S. 2006. Toxidade de óleos essenciais de Piper aduncum e Piper hispidinervum em Sitophilus zeamais. Pesquisa Agropecuária Brasileira, 41: 217-222.

Fazolin, M.; Estrela, J.L.V.; Catani, V.; Alércio, M.R.; LIMA, M.S. 2007. Atividade inseticida do óleo essencial de Tanaecium nocturnum (Barb. Rodr.) Bur. \& K. Shum (Bignoneaceae) sobre Sitophilus zeamais Motsch. (Coleoptera: Curculionidae). Acta Amazonica, 37: 599-604.

Ferreira, D.F. 2000. Manual do sistema Sisvar para análises estatísticas. Universidade Federal de Lavras, Lavras, Minas Gerais. 66 pp.

Gottlieb, O.R.; Koketsu, M.; Magalhães, M.T.; Maia, J.G.S.; Mendes, A.I.R.; Silva, M.L.; Wilberg, V.C. 1981. Óleos essenciais da Amazônia. Acta Amazonica, 11: 143-148.

Gupta, S.; Kaisheva, E. 2003. Development of multidose formulation for humanized monoclonal antibody using experimental design techniques. AAPS PharmaSci, 5: 8.

Jham, G.N.; Dhingra, O.D.; Jardim, C.M.; Valente, V.M.M. 2005. Identification on the major fungitoxic component of Cinnamon bark oil. Fitopatologia Brasileira, 30: 404-408.

Krebs, H.A.; Wiggins, D.; Stubbs, M.; Sols, A.; Bedoya, F. 1983. Studies on the mechanism of the anti-fungal action of benzoate. Biochemical Journal, 214: 657-663.

Kumar, A.; Shukla, R.; Singh, P.; Prasad, C.S.; Dubey, N.K. 2008. Assessment of Thymus vulgaris L. essential oil as a safe botanical preservative against post harvest fungal infestation of food commodities. Innovative Food Science and Emerging Technologies, 9: $575-580$.

Lima, M.P.; Zoghbi, M.G.B.; Andrade, E.H.A.; Silva, T.M.D.; Fernandes, C.S. 2005. Constituintes voláteis das folhas e dos galhos de Cinnamomum Zeylanicum Blume (Lauraceae). Acta Amazonica, 35: 363-366.

Ming, L.C. 1995. Levantamento de plantas medicinais na reserva extrativista Chico Mendes - Acre. Tese de Doutorado, Universidade Estadual Julho de Mesquita Filho, Botucatu, São Paulo. 192 pp.

Mohsenin, N.N. 1970. Physical properties of plant and animal materials. Gordon and Breach Science, New York. 734 pp.

Muller, C.H.; Figueredo, F.J.C.; Kato, A.K.; Carvalho, J.E.U.; Stein, R.L.B.; Silva, A. 1995. A cultura da castanha-do-brasil. EMBRAPA, Brasília. 65 pp.

Muller-Riebau, F.; Berger, B.; Yegen, O. 1995. Chemical-composition and fungitoxic properties to phytopathogenic fungi of essential oils of selected aromatic plants growing wild in Turkey. Journal of Agricultural and Food Chemistry, 43: 2262-2266.
Naakahara, K.; Alzoreky, N.S.; Yoshihashi, T.; Nguyen, H.T.T.; Trakoontivakorn, G. 2003. Chemical composition and antifungal activity of essential oil from Cymbopogon nardus (citronella grass). Japan Agricultural Research Quartely, 37: 249-252.

Pereira, M.C. 2001. Efeito da adição de condimentos no controle de microorganismos, na conservação de produtos de panificação e na inibição de metabólitos produzidos por fungos associados ao café. Dissertação de Mestrado, Universidade Federal de Lavras, Lavras, Minas Gerais. 104 pp.

Pimentel, F.A.; Cardoso, M.G.; Salgado, A.P.S.P.; Aguiar, P.M.; Silva, V.F.; Morais, A.R.; Nelson, D.L. 2006. A convenient method for the determination of moisture in aromatic plants. Quimica Nova, 29: 373-375.

Pimentel, F.A.; Zacaroni, L.M.; Andrade, M.A.; Guimarães, L.G.L.; Salgado, A.P.S.P.; Freire, J.M.; Muniz, F.R. 2008. Influência da temperatura de secagem sobre o rendimento e a composição química do óleo essencial de Tanaecium nocturnum (Barb. Rodr.) Bur. \& K. SHUM. Quimica Nova, 31: 523-526.

Pitt, J.I.; Hocking, A.D. 1999. Fungi and food spoilage. Aspen Publishers, Gaithersburg, MD, USA. 220 pp.

Pletsch, M.; Sant'ana, A.E.G. 1995. Secoundary compound accumulation in plants - The application of plant biotechnology to plant improvement. Chemistry of the Amazon ACS Symposium Series, 588: 51-64.

Schoch, T.J.; Leach, W.H. 1964. Determination of Absolute Density Liquid Displacement. In: Whestles, R.L.; Wolfrom, M.L. (Eds). Methods in Carbohydrates Chemistry. Vol. 4. Academic Press, New York, USA. p. 101-103.

Silva, G.H.; Teles, H.L.; Trevisan, H.C.; Bolzani, V.S.; Young, M.C.M.; Pfenning, L. H.; Eberlin, M.N.; Haddad, R.; CostaNeto, C.M.; Araújo, A.R. 2005. New bioactive metabolites produced by, Phomopsis cassiae, and endophytic fungus in Cassia spectabilis. Journal of Brazilian Chemical Society, 16: 1463-1466.

Souza, J.M.L. 2004. Manual de segurança e qualidade para a cultura da castanha-do-brasil. CampoPAS, Brasília, Distrito Federal. 60 pp.

Souza, M.L. 1984. Estudos de processos tecnológicos para a obtenção de produtos derivados de castanha-do-Brasil (Bertholletia excelsa, $H$. B. K.). Dissertação de Mestrado, Universidade Federal do Ceará, Fortaleza, Ceará. 139 pp.

Suhr, K.I.; Nielsen, P.V. 2003. Antifungal activity of essential oils evaluated by two different application techniques against rye spoilage fungi. Journal of Applied Microbiology, 94: 665-674.

Vaughn, S.F.; Spencer, G.F. 2004. Antifungal activity of natural compounds against thiabendazole resistant fusariung-sambucinum strains. Journal of Agricultural and Food Chemistry, 42: 200203.

Viegas, E.C.; Soares, A.; Carmo, M.G.F.; Rossetto, C.A.V. 2005. Toxidade de óleos essenciais de alho e casca de canela contra fungos do grupo Aspergillus flavus. Horticultura Brasileira, 23: 915-919. 


\section{ACTA}

Wang, S.Y.; Chen, P.F.; Chang, S.T. 2005. Antifungal activities of essential oils their constituents from indigenous cinnamom (Cinnamomum osmoplaloeum) leaves against wood decay fungi. Bioresource Tecnology, 96: 813-818.

Wink, M. 1990. Physiology of secundar product formation in plants. In: Charlwood, B.V.; Rhodes, M.J.C, (Eds). Secondary products plant tissue culture. Oxford: University Press, New York. p. 23-42.

Recebido em 13/03/2009

Aceito em 04/08/2009 
